\title{
Sistem Pendukung Keputusan Pengadopsian Anak Menggunakan Metode Analytical Hierarchy Process Dan Metode Perbandingan Eksponensial
}

\author{
Ajeng Dhanty Yosima1); Dwi Remawati ${ }^{2)}$; Muhammad Hasbi3) \\ 1)Program Studi Sistem Informasi, STMIK Sinar Nusantara \\ 2)Program Studi Teknologi Informasi , STMIK Sinar Nusantara \\ 3)Program Studi Informatika, STMIK Sinar Nusantara \\ 1)ajengyosima1@gmail.com; 2)dwirema@sinus.ac.id; 3)mhasbi@sinus.ac.id
}

\begin{abstract}
YPAB is an institution that keeps and takes care babies and children who don't have parents. The babies and the children can be adopted, but the institution has their own regulations for potential adopters who want to adopt children. All this time, adopter who adopted the babies or the children from YPAB institution is done manually which need long time. Therefore, DSS is needed for decide a potential adopter. The purpose of this research is developing a DSS in the process of selecting potential adopters. Meanwhile, the research method uses the Analytical Hierarchy Process (AHP) and the Exponential Comparison Method (MPE) and the System testing uses black-box and validity testing. System testing is used black-box and validity testing by comparing the real YPAB data and the calculation system results. The test results show that the adoption system using the Analytical Hierarchy Process (AHP) method and the Exponential Comparison Method (MPE) has a good performance so that the system is feasible to be implemented in YPAB.
\end{abstract}

Keywords: DSS, MPE, Children adoption, YPAB.

\section{PENDAHULUAN}

YPAB adalah sebuah yayasan yang menampung anak/bayi yang dititipkan oleh orangtuanya agar bisa diadopsi oleh orang lain. Yang mengejutkan, sebagian besar anak-anak yang ditampung di panti tersebut bukan anakanak yang ditelantarkan orang tuanya, justru sebagian besar dari mereka adalah anak-anak dari kalangan terpelajar, kalangan berada, namun memiliki anak yang tidak diinginkan. YPAB menampung 23 anak yang dirawat oleh 10 perawat. Sementara daya tampung panti tersebut maksimal dihuni oleh 35 anak. Pada YPAB banyak yang mendaftar sebagai calon pengadopsi anak/ bayi. Dalam proses pemilihan calon pengadopsi yang memperebutkan hak asuh anak terhadap satu anak yang ada di YPAB, terdapat 10 hingga 15 calon pengadopsi yang mengajukan persyarakat dan saling memperebutkan hak asuh anak terhadap satu anak. Selama ini proses penentuan pengadopsi menggunakan sistem manual yaitu berdasarkan urutan mendaftar sebagai calon pengadopsi. Hal ini akan sangat memerlukan waktu yang lama bagi pihak YPAB dalam pengambilan keputusan.

Referensi Penelitian sebelumnya dengan menggunakan metode Analytical Hierarchy Process (AHP) digunakan untuk penilian soft skill karyawan[1], penentuan penerima
Jamkesmas [2], penentuan pemilihan Presiden RI 2019 [3], sedangkan penelitian yang menggunan Metode Perbandingan Eksponensial digunakan untuk penentuan supplier dan produk yang menguntungkan[4], juga digunakan untuk menentukan kualitas gula tumbu[5], sedangkan penggunaan metode AHP dan metode Perbandingan Eksponensial digunakan untuk menentukan pemilihan sekolah anak.[6].

Penelitian ini membuat sebuah Sistem Pendukung Keputusan Pengadopsian Anak Menggunakan Metode Analytical Hierarchy Process (AHP) dan Metode Perbandingan Eksponensial dengan beberapa kriteria yang harus dimiliki oleh calon pengadopsi sehingga akan mempermudah dalam penentuan calon pengadopsi anak/bayi.

\section{TINJAUAN PUSTAKA}

\subsection{Penelitian Sebelumnya}

Pada penelitian ini menjelaskan bahwa Metode Perbandingan Eksponensial dapat digunakan untuk menentukan pilihan asuransi investasi. Untuk melakukan perbandingan dan meningkatkan pengetahuan maka diperlukan metode sistem penunjang keputusan sehingga mudahnya mengetahui kelebihan maupun kekurangan investasi di suatu perusahaan 
asuransi, setelah mengetahui pebandingan dapat menentukan pilihan lebih mudah, tetapi dengan memutuskan pilihan secara pasti bisa dengan mengetahui keseluruhan fungsi dari aspek - aspek penilaian ataupun kriteria dari asuransi investasi tersebut [7].

Penelitian berikut dilakukan untuk menyelesaikan permasalahan yang terdapat pada jurnal tersebut yaitu tidak ada perhitungan khusus dan pembobotan setiap kriteria untuk menentukan penerima beasiswa siswa berprestasi. Tujuan penelitian tersebut untuk membuat keputusan yang diperoleh dapat lebih akurat. Metode yang digunakan adalah Metode Perbandingan Eksponensial (MPE). Ada beberapa tahap seperti pengumpulan data, analisa sistem, perancangan pemodelan dan implementasi sistem. Hasil dari penilitian ini adalah hasil alternatif akan ditentukan dari total nilai yang didapatkan dari penjumlahan konversi nilai setiap kriteria dan sub kriteria kemudian dipangkatkan dengan tingkat kepentingan setiap kriteria (bobot) yang telah ditentukan pengambil keputusan [8].

Penelitian ini dilakukan untuk menyelesaikan permasalahan yang terdapat pada jurnal tersebut yaitu seringnya tender ulang atau tender tidak mencukupi syarat sah tender dikarenakan kurang tepat pemilihan supplier yang akan diundang, terutama untuk pengadaan barang yang bersifat rutin yaitu barang consumable. Tujuan Penelitian ini diharapkan menjadi alternatif dalam pemilihan supplier barang consumable dengan kriteria yang menjadi prioritas pertimbangan departemen pengadaan barang dalam memilih supplier barang consumable sekaligus mengetahui best supplier barang consumable di departemen pengadaan barang. Metode yang digunakan adalah metode [9].

Penelitian ini dilakukan untuk menyelesaikan permasalahan yang terdapat pada jurnal tersebut yaitu banyaknya jumlah Rumah Makan yang menyediakan masakan khas Padang khususnya di kota Padang, dapat menyebabkan para wisatawan maupun masyarakat kesulitan dalam memilih atau mendapatkan informasi terkait Rumah Makan yang sesuai dengan kriteria. Oleh sebab itu dibutuhkan suatu sistem pendukung keputusan pemilihan tempat kuliner sebagai salah satu alternatif pengambilan keputusan. Metode yang digunakan adalah MPE yang menghasilkan web dengan berbagai tampilan seperti Halaman Utama yang terdiri dari (header web, pilihan menu, slide serta form input nilai kriteria). Halaman Petunjuk Sistem yang menampilkan info penggunakan SPK. Halaman Login menampilkan akses login yang hanya dapat diakses oleh pengelola atau petugas. Halaman admin berguna untuk menambah, mengedit data dan menghapus data pada database. Menu entry data rumah makan merupakan halaman yang menampilkan daftar rumah makan. Menu entry data kriteria merupakan halaman yang menampilkan daftar kriteria rumah makan dan sekaligus berfungsi untuk penambahan, perubahan dan penghapusan data kriteria rumah makan. Menu entry data subkriteria merupakan halaman yang menampilkan daftar subkriteria rumah makan dan sekaligus berfungsi untuk penambahan, perubahan dan penghapusan data subkriteria rumah makan. Proses Perhitungan Nilai dengan Menggunakan Metode Perbandingan Eksponensial (MPE). Perhitungan pada sistem dilakukan pada halaman entry nilai $\mathrm{rm}$, ada beberapa kriteria dan subkriteria yang tersedia pada form. Untuk melakukan proses perhitungan nilai rumah makan sebagai alternatif yang tersedia yang telah di entrykan sebelumnya oleh admin bisa dengan memilih option angka yang telah tersedia pada setiap subkriteria. Hasil penelitian ini adalah Aplikasi yang sudah dibuat memberikan suatu rekomendasi alternatif keputusan tempat kuliner di kota Padang berdasarkan kriteria, dengan menggunakan MPE agar konsumen lebih mudeng untuk memilih tempat makan yang diinginkan dan tidak mengalami kesulitan di Kota Padang. [10]

\subsection{Analytical Hierarchy Process}

Analytical Hierarchy Process memiliki hirarki yang komplek antara lain tujuan, kriteria, subkriteria perhitungannya sampai level yang paling bawah dari subkriteria tersebut[11].

Secara umum pengambilan keputusan dengan metode AHP didasarkan pada langkah - langkah berikut:

a. Mendefinisikan masalah dan menentukan solusi yang diinginkan.

b. Membuat matriks perbandingan berpasangan.

Bila diketahui nilai $\left(a_{i j}\right)$ maka secara teoritis nilai :

$a_{i j}=\frac{1}{a_{i j}}$ dan $a_{i j}=1$, dalam situasi $\mathrm{i}=\mathrm{j}$, dalam hal ini berarti $a_{11}=1, a_{22}=1, a_{33}=$ 1 , dan $a_{44}=1$

c. Menghitung vector eigen normalisasi.

Perhitungan nilai vektor eigen normalisasi ini dilakukan untuk semua perbandingan berpasangan. Nilai ini 
merupakan bobot setiap elemen untuk penentuan prioritas elemen-elemen dari setiap matriks perbandingan berpasangan. Hal-hal yang dilakukan dalam langkah ini adalah:

1. Menjumlahkan nilai setiap kolom pada matriks.

2. Lalu membagi setiap nilai dari kolom dengan total kolom yang bersangkutan untuk memperoleh normalisasi matriks. $\frac{\text { Nilai kolom kriteria }}{\text { total Kolom }}$

3. Selanjutnya menjumlahkan nilai-nilai dari setiap baris dan membaginya dengan jumlah kriteria untuk mendapatkan rata-rata.

$$
\lambda=\frac{\text { total baris }}{\text { jumlah } \text { kriteria }}
$$

4. Menentukan nilai eigen maksimal.

5. Melakukan perhitungan consistency index $(\mathrm{Cl})$ dengan rumus :

$\mathrm{CI}=\frac{\lambda m a k s-n}{n-1}$

Dimana $\mathrm{n}=$ banyaknya kriteria.

6. Melakukan perhitungan consistency rasio $(C R)$ dengan rumus:

$\mathrm{CR}=\frac{C I}{I R}$

Dimana $\mathrm{CR}=$ Consistency Ratio

$\mathrm{Cl}=$ Consistency Index

$\mathrm{IR}=$ Index Random Consistency

\subsection{Metode Perbandingan Exponensial}

Metode Perbandingan Exponensial (MPE) adalah salah satu metode dari Decision Suport System (DSS) yang digunakan untuk menentukan urutan prioritas alternatif keputusan dengan kriteria jamak. Dengan perhitungan secara eksponensial, perbedaan nilai antara kriteria dapat dibedakan tergantung kepada kemampuan orang yang menilai. MPE merupakan salah satu metode pengambilan keputusan yang mengkuantifikasikan pendapat seseorang atau lebih dalam skala tertentu. Teknik ini digunakan untuk membantu individu pengambil keputusan untuk menggunakan rancang bangun model yang terdefinisi dengan baik pada tahapan proses. MPE akan menghasilkan nilai alternatif yang perbedaannya lebih kontras. Untuk menggunakan metode MPE terdapat beberapa langkah dalam pemilihan keputusan denggan menggunakan MPE berikut[12]:

1. Menentukan kriteria atau perbandingan relatif kriteria keputusan yang penting untuk di evaluasi dengan menggunakan skala konversi tertentu sesuai dengan keinginan pengambil keputusan.

2. Menentukan tingkat kepentingan relatif dari setiap kriteria keputusan atau pertimbangan kriteria. Penentuan bobot di tetapkan pada setiap kriteria untuk menunjukan tingkat kepentingan suatu kriteria.

3. Menyusun alternatif-alternatif keputusan yang akan dipilih.

4. Melakukan penilaian terhadap semua alternatif pada tiap kriteria dalam bentuk total skor tiap alternatif.

5. Menghitung skor atau nilai total setiap alternatif dan mengurutkannya. Semakin besar Total Nilai (TN) alternatif maka semakin tinggi urutan prioritasnya.Total Nilai alternatif maka semakin tinggi urutan prioritasnya. Formulasi perhitungan MPE TotalNilai $\left(T N_{i}\right) \sum_{j=1\left(R K_{i j}\right)}^{m} T K K_{j}$

Keterangan :

$\mathrm{TNi}=$ Total nilai alternatif ke-i

RKij = Derajat kepentingan relative kriteria ke-j pada pilihankeputusan ke-i

$\mathrm{TKKj}=$ Derajat kepentingan kriteria keputusan ke-j TKKJ>0;bulat

$\mathrm{N} \quad=$ Jumlah pilihan keputusan

$\mathrm{M}=$ Jumlah kriteria keputusan

\section{METODE PENELITIAN}

Metode penelitian merupakan tahap-tahap yang dilalui peneliti dalam pelaksanaan penelitian agar hasil yang dicapai tidak menyimpang dari tujuan. Penelitian beserta sumber data diambil dari YPAB. Adapun langkah - langkah dalam penelitian ini dibagi menjadi 6 seperti berikut:

1. Sumber Data

Data pada penelitian ini menggunakan Data sekunder. Data Sekunder adalah data yang diperoleh dari pengumpulan data secara langsung dengan pihak yang bersangkutan dengan menggunakan metode wawancara atau observasi.

2. Metode Pengumpulan Data

a. Metode Observasi

Terjun langsung ke instansi Yayasan Pemeliharaan Anak dan Bayi, observasi dilakukan guna melihat langsung situasi dan kondisi yang sedang terjadi.

b. Metode Wawancara

Pengumpulan data yang dilakukan dengan wawancara, dengan mengajukan pertanyaan dengan detail kepada pihak terkait yang berwenang. 
Dilakukan dengan lisan sehingga dijawab dengan lisan.

c. Metode Kepustakaan

Metode Kepustakaan adalah cara mengumpulkan data dengan menggunakan pustaka-pustaka yang telah ada untuk digunakan sebagai referensi.

3. Perancangan Sistem

Perancangan sistem meliputi 4 tahap berikut:
a. Usecase Diagram
b. Sequence Diagram
c. Class Diagram
d. Activity Diagram

4. Desain

Pada tahap ini penulis akan membuat desain sistem aplikasi berikut:

a. Desain Input

Dalam desain input berbentuk beberapa menu antara lain :

1) Menu Login

Menu login ini digunakan untuk masuk ke dalam sistem. Menu ini menampilkan Username dan Password yang berfungsi untuk pengamanan sistem.

2) Menu Data Calon Pengadopsi Pada menu Data Pengadopsi (Alternatif) menambah data calon pengadopsi dapat menginput pekerjaan suami, gaji, usia suami, dan usia pernikahan.

3) Menu Proses penilaian dengan metode AHP dan MPE.

Setelah data calon pengadopsi diinputkan berikutnya adalah memberikan penilaian calon pengadopsi tersebut dengan metode AHP dan MPE.

5. Pengujian

Pengujian sistem dilakukan dengan uji fungsionalitas. Pengujian sistem dengan uji fungsionalitas yaitu dengan menggunakan metode BlackBox. BlackBox yang merupakan metode pengujian di mana data tes berasal dari persyaratan fungsional yang ditentukan tanpa memperhatikan struktur program akhir[13]. Uji validitas membandingkan hasil pemilihan pengadopsi sebelum menggunakan SPK dan hasil pemilihan pengadopsi setelah menggunakan SPK.

\section{HASIL DAN PEMBAHASAN}

\subsection{Perhitungan Metode AHP}

Perhitungan AHP digunakan untuk menghitung bobot kriteria, tahap pertama yaitu Skala Penilaian Perbandingan Berpasangan dapat dilihat pada Tabel 1.

Tabel 1. Skala perbandingan berpasangan

\begin{tabular}{|l|c|c|c|c|}
\hline Kriteria & $\begin{array}{l}\text { Pekerjaan } \\
\text { Suami }\end{array}$ & Gaji & $\begin{array}{l}\text { Umur } \\
\text { Suami }\end{array}$ & $\begin{array}{l}\text { Umur } \\
\text { Pernikahan }\end{array}$ \\
\hline $\begin{array}{l}\text { Pekerjaan } \\
\text { Suami }\end{array}$ & 1 & 1 & 3 & 5 \\
\hline Gaji & 1 & 1 & 5 & 5 \\
\hline $\begin{array}{l}\text { Umur } \\
\text { Suami }\end{array}$ & 0.33 & 0.20 & 1 & 1 \\
\hline $\begin{array}{l}\text { Umur } \\
\text { Pernikahan }\end{array}$ & 0.20 & 0.20 & 1 & 1 \\
\hline
\end{tabular}

Selanjut menghitung ke langkah berikutnya dengan metode AHP dan menghasilkan bobot yang dapat dilihat pada Tabel 2.

Tabel 2. Bobot Kriteria

\begin{tabular}{|l|l|}
\hline Kriteria & Bobot \\
\hline Pekerjaan Suami & 0.3820 \\
\hline Gaji & 0.4320 \\
\hline Umur Suami & 0.0996 \\
\hline Umur Pernikahan & 0.0864 \\
\hline
\end{tabular}

Setelah menghitung bobot kriteria langkah selanjutnya menghitung perangkingan menggunakan MPE.

\subsection{Perhitungan Metode MPE}

Metode MPE digunakan untuk menghitung perangkingan alternatif, terdapat 15 Alternatif pada calon pengadopsi YPAB yang akan memperebutkan hak asuh terhadap satu anak yang ada di YPAB. Berdasarkan perbandingan data rill dan perhitungan sistem, dari 15 alternatif ada 3 besar alternatif yang layak namun disini keputusan hanya ada satu alternatif yang mendapatkan hak asuh anak yaitu Alternatif 13 yang nilainya paling tinggi dari 3 besar alternatif tersebut. Merujuk pada rumus MPE (6) Perhitungan perangkingan alternatif. Hasil perhitungan MPE dapat dilihat pada Tabel 3.

Tabel 3.Perangkingan alternatif.

\begin{tabular}{|c|c|c|}
\hline $\begin{array}{c}\text { Nama } \\
\text { Alternatif }\end{array}$ & $\begin{array}{c}\text { Total } \\
\text { Nilai }\end{array}$ & Rangking \\
\hline Alternatif 13 & 5.7335 & 1 \\
\hline Alternatif 8 & 5.7171 & 2 \\
\hline Alternatif 1 & 5.6894 & 3 \\
\hline Alternatif 6 & 5.6339 & 4 \\
\hline Alternatif 9 & 5.5844 & 5 \\
\hline Alternatif 12 & 5.4689 & 6 \\
\hline Alternatif 10 & 5.3384 & 7 \\
\hline Alternatif 5 & 5.2769 & 8 \\
\hline Alternatif 14 & 5.2713 & 9 \\
\hline
\end{tabular}




\begin{tabular}{|c|c|c|}
\hline $\begin{array}{c}\text { Nama } \\
\text { Alternatif }\end{array}$ & $\begin{array}{c}\text { Total } \\
\text { Nilai }\end{array}$ & Rangking \\
\hline Alternatif 4 & 5.1289 & 10 \\
\hline Alternatif 11 & 5.0586 & 11 \\
\hline Alternatif 3 & 5.0262 & 12 \\
\hline Alternatif 2 & 4.5264 & 13 \\
\hline Alternatif 15 & 4.1773 & 14 \\
\hline Alternatif 7 & 4.1480 & 15 \\
\hline
\end{tabular}

Pada Tabel 3, Nilai Total tertinggi diperoleh alternatif 13 dengan Total Nilai 5.7335 yang lolos dan mendapatkan hak asuh anak terhadap satu anak "Anak 1" yang ada di YPAB.

\subsection{Perancangan Sistem}

\section{Use Case Diagram}

Use case diagram menggambarkan sebuah interaksi antara satu dengan yang lainnya atau lebih aktor dengan sistem yang dibuat. Use case diagram digunakan untuk mengetahui fungsi apa saja yang ada didalam sebuah sistem dan siapa saja yang berhak menggunakan fungsi-fungsi menu yang ditunjukkan pada Gambar 1.

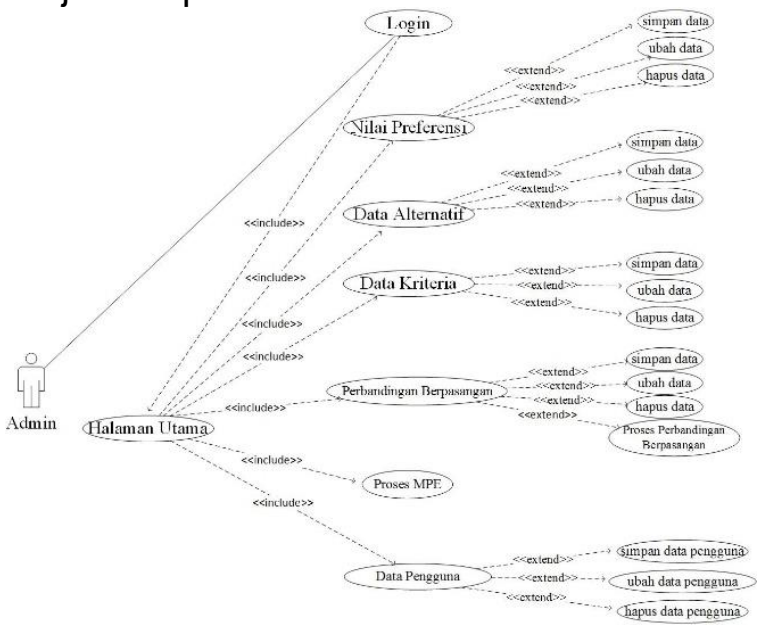

Gambar 1. Use Case Diagram.

\section{Sequence Diagram}

Sequence Diagram menggambarkan interaksi objek dan memberi petunjuk atau tanda komunikasi diantara objek-objek tersebut. Berikut ini Squence Diagram yang terdapat pada Sistem Pendukung Keputusan Yayasan Pemeliharaan anak dan Bayi dapat dilihat pada Gambar 2.

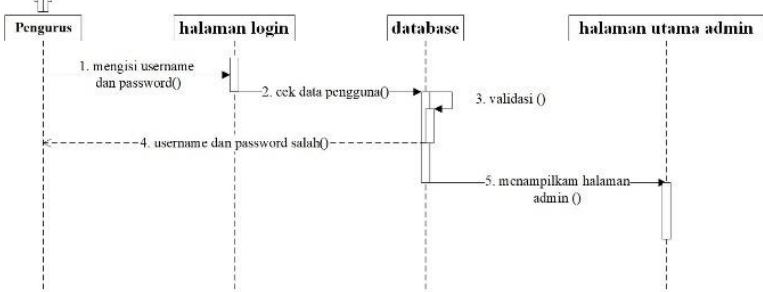

Gambar 2. Sequence Diagram Login
Pada Gambar 2 dapat dilihat bahwa untuk melakukan login admin memasukkan username dan password, setelah itu sistem akan mengecek username dan password ke dalam database apabila username dan password valid maka akan tampil halaman utama admin.

Setelah login, admin dapat menyimpan data kriteria. Admin harus mengisi kriteria yang sudah ditentukan sebelumnya yaitu Kode Kriteria, Pekerjaan Suami, Gaji, mur Suami, dan Umur Pernikahan yang dapat dilihat pada Gambar 3.

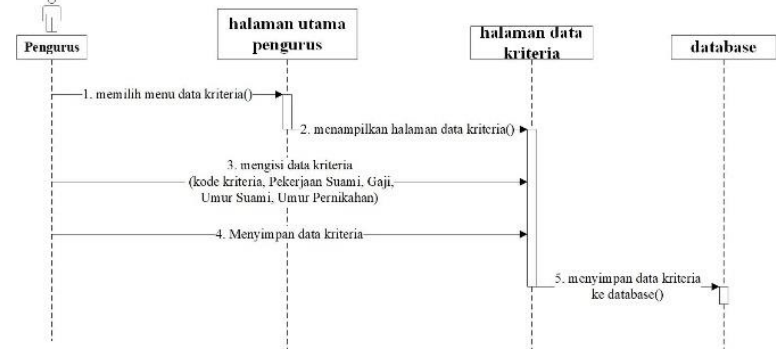

Gambar 3. Sequence Diagram Simpan Data

Pada Gambar 3 dapat dilihat apabila admin ingin menambahkan data kriteria, admin harus memilih menu kriteria setelah itu sistem menampilkan halaman data kriteria, selanjutnya admin mengisi data kriteria yaitu Kode Kriteria, Pekerjaan Suami, Gaji, Umur Suami, Umur Pernikahan. Setelah mengisi data tersebut klik tombol simpan, maka sistem menyimpan data kriteria ke database.

\section{Class Diagram}

Class Diagram merupakan suatu model untuk menggambarkan struktur dan deskripsi class beserta hubungan satu sama lain. Class menggambarkan keadaan (atribut) suatu sistem, sekaligus menawarkan layanan untuk manipulasi atribut tersebut (metoda). Berikut ditunjukkan pada Gambar 4 Class Diagram Sistem Pendukung Keputusan Pengadopsian Anak pada YPAB.

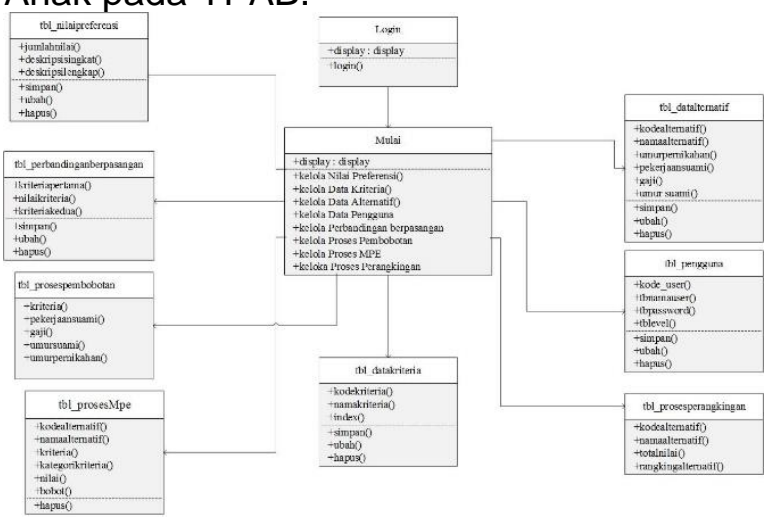

Gambar 4. Class Diagram 
Pada Gambar 4 dapat dilihat bahwa class diagram saling berelasi. Login adalah hal utama yang harus dilakukan untuk masuk pada sistem, apabila tidak memiliki hak akses atau username dan password maka tidak dapat masuk pada sistem aplikasi. Selanjutnya nilai preferensi, apabila tidak mengisi nilai preferensi dan tidak menentukan proses berbandingan maka proses perhitungan pembobotan perkriteria tidak dapat dilakukan. Selanjutnya data kriteria juga berelasi dengan proses pembobotan karena pembobotan yang diproses adalah pembobotan setiap kriteria yang sudah ditentukan. Selanjutnya pada data alternatif, data alternatif yaitu data calon pengadopsi apabila tidak mengisi data alternatif atau tidak mengisinya dengan lengkap maka sistem tidak akan bisa memproses perangkingan pada seluruh alternatif. Selanjutnya data pengguna, apabila data pengguna tidak terdapat pada tabel maka admin tidak akan bisa masuk pada sistem aplikasi. Selanjutnya Proses MPE dilakukan sebelum memproses perangkingan, dimana proses MPE memilih alternatif-alternatif yang akan dihitung Total Nilai nya. Apabila ada data alternatif yang ada dihapus maka pada proses MPE jumlah alternatif menyesuaikan jumlah data alternatif. Selanjutnya proses perankingan, apabila tidak memilih alternatif yang akan diproses perangkingan, maka tidak akan menampilkan halaman perangkingan karena tidak ada alternatif yang diproses.

\section{Activity Diagram}

Activity Diagram pada aplikasi Sistem Pendukung Keputusan dapat dilihat pada Gambar 5.

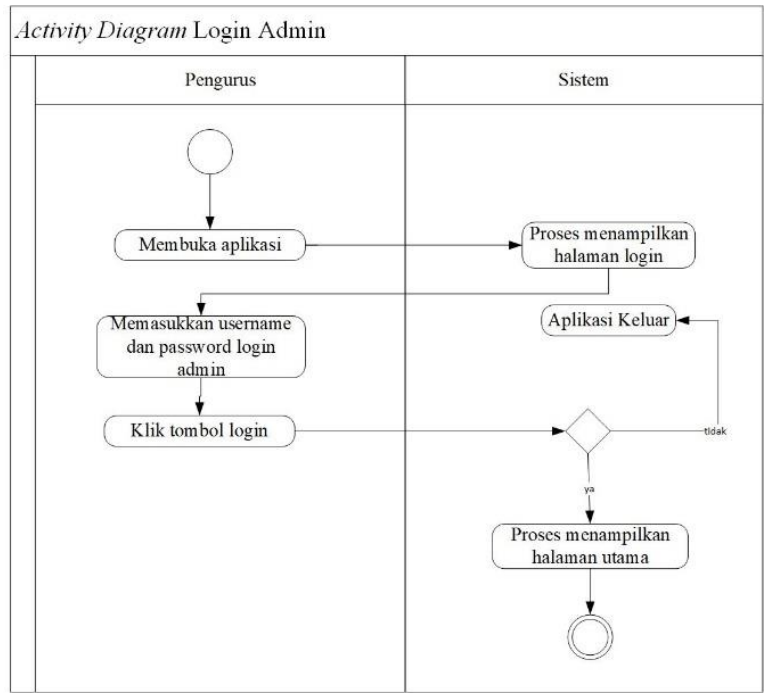

Gambar 5. Activity Diagram Login
Pada Gambar 5 Activity Diagram dimulai dengan admin membuka aplikasi kemudian sistem menampilkan halaman login. Admin memasukkan username dan password. Jika data yang dimasukkan salah maka aplikasi tidak mau masuk halam utama.

\subsection{Implementasi Sistem}

Implementasi sistem pada aplikasi Sistem Pendukung Keputusan terdapat menu Data Pengguna menu tersebut beirisi kode user, nama user, password dan level. Dimana data pengguna tersebut hanya untuk admin yang akan mengakses sistem aplikasi itu. Berikut ditunjukkan pada Gambar 6 Data Pengguna.

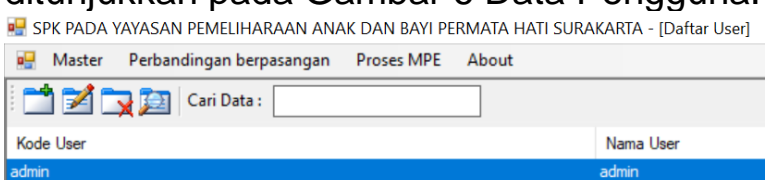

\section{Gambar 6. Data Pengguna}

Di dalam menu Nilai Preferensi berisi tentang nilai-nilai yang sudah ditentukan pada rumus AHP. Terdiri dari mengisi nilai, deskripsi singkat, dan deskripsi lengkap. Berikut ditunjukkan pada Gambar 7 Nilai Preferensi.

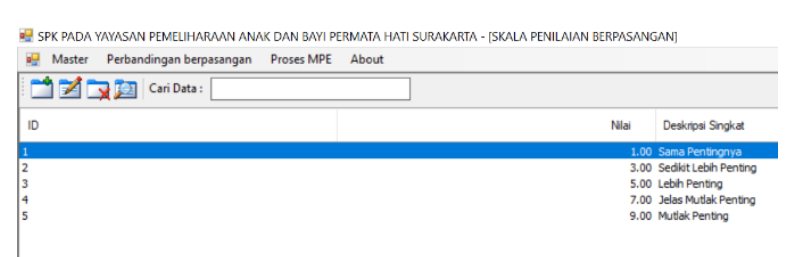

Gambar 7. Menu Nilai Preferensi

Di dalam menu Data Kriteria dimana admin harus mengisi kode kriteria, nama kriteria, dan index. Index sendiri hanya untuk menjelaskan bahwa kriteria urutan teratas indexnya satu, untuk seterusnya indexnya akan semakin besar. Namun index ini tidak berpengaruh untuk perhitungan sistem. Berikut ditunjukkan pada Gambar 8 Data Kriteria.

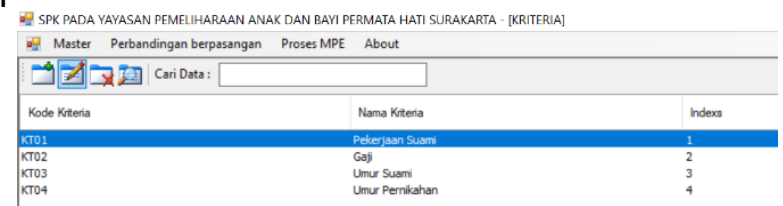

Gambar 8. Halaman Data Kriteria

Menu Data Alternatif berfungsi untuk menginput data alternatif-alternatif atau calon pengadopsi seperti kode alternatif, nama alternatif, umur pernikahan, pekerjaan suami, gaji, dan umur suami, yang mengajukan persyaratan untuk mendapatkan hak asuh anak 
mereka terhadap anak dari YPAB. Berikut ditunjukan pada Gambar 9 dan Gambar 10 Halaman Data alternatif.

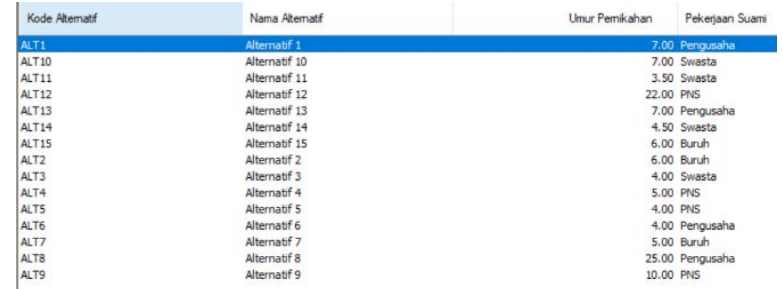

Gambar 9. Halaman Data Alternatif

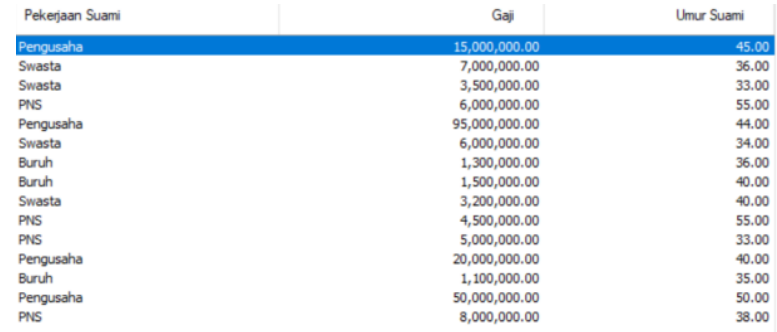

Gambar 10. Halaman Data Alternatif

Di dalam menu Perbandingan Berpasangan yang berisi kode perbandingan, dan perbandingan, dimana untuk menentukan hasil pembobotan per kriteria harus menentukan perbandingan berpasangan terlebih dahulu. Setelah menentukan perbandingan berpasangan, klik tombol proses pembobotan sistem akan memproses perhitungan pembobotan dan menampilkan hasil pembobotan. Berikut ditunjukkan pada Gambar 11, Gambar 12 dan Gambar 13 Perbandingan Berpasangan.

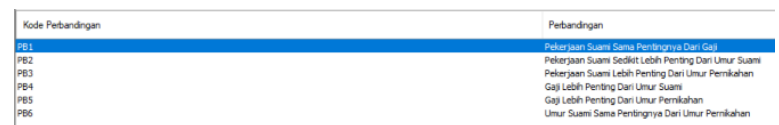

Gambar 11. Halaman Perbandingan MATRIX PERBANDINGAN BERPASANGAN

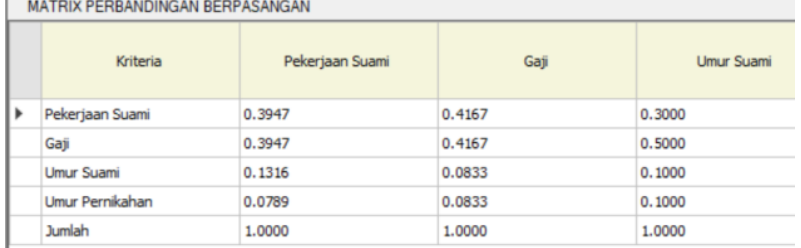

Gambar 12. Halaman Perbandingan

\begin{tabular}{|l|l|l|}
\multicolumn{1}{|c|}{ Umur Pernikahan } & \multicolumn{1}{|c|}{ Jumlah Baris } & Rata Rata / Bobot \\
\hline 0.4167 & 1.5281 & 0.3820 \\
\hline 0.4167 & 1.7281 & 0.4320 \\
\hline 0.0833 & 0.3982 & 0.0996 \\
\hline 0.0833 & 0.3456 & 0.0864 \\
\hline 1.0000 & 4.0000 & \\
\hline
\end{tabular}

Gambar 13. Halaman Perbandingan

Menu Proses MPE dimana tampilan tersebut memilih alternatif-alternatif yang akan diproses MPE sebelum akhirnya akan menampilkan perangkingan dari seluruh alternatif. Apabila ada alternatif yang tidak jadi diproses tapi sudah dipilih admin dapat menghapus dengan cara klik tombol delete. Berikut ditunjukkan pada gambar Gambar 14 dan Gambar 15 Proses MPE dan Gambar 16 perangkingan.

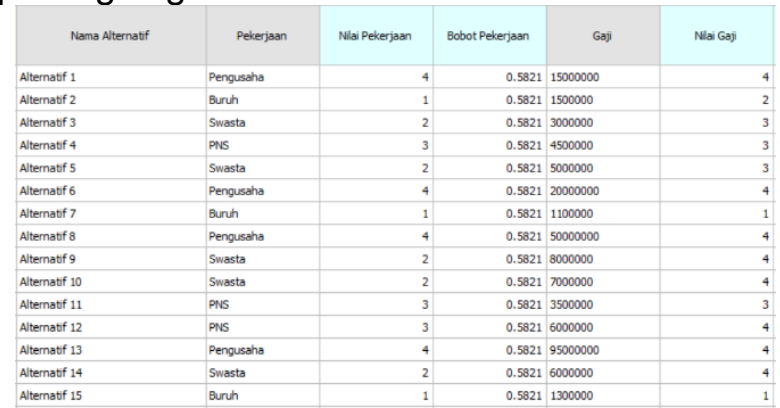

Gambar 14. Halaman Proses MPE

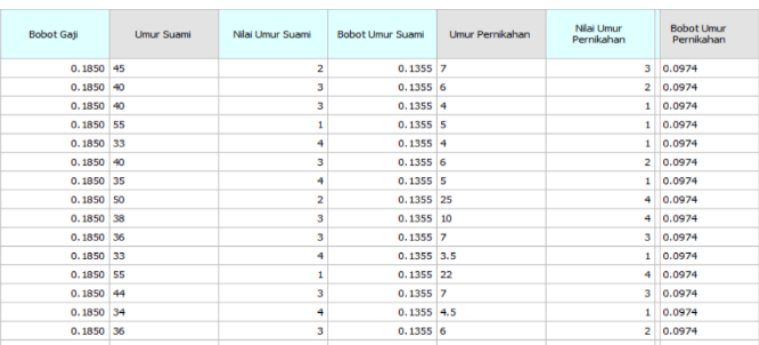

Gambar 15. Halaman Proses MPE

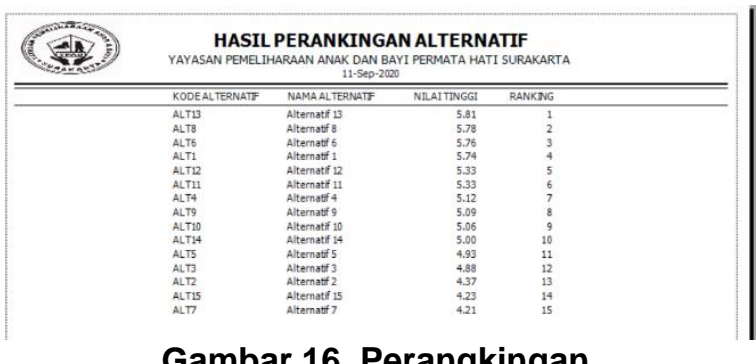

\subsection{Uji Validitas}

Dari hasil data riil dan hasil perhitungan sistem tersebut, dimana akan menghasilkan perbandingan antara hasil output sistem dengan hasil keputusan yang di hasilkan di lembaga YPAB. Dari 15 alternatif ada 3 besar alternatif yang layak namun disini keputusan hanya ada satu alternatif yang mendapatkan hak asuh anak yaitu Alternatif 13 yang nilainya lebih tinggi dari 3 besar alternatif tersebut. Alternatif 13 sangat layak untuk mendapatkan hak asuh anak. hasilnya sama dengan data riil calon pengadopsi yang mendapatkan hak asuh anak dari YPAB. Hasil perbandingan dilihat pada Tabel 4. 
Tabel 4. Hasil Uji Validitas Data Riil Dan Perhitungan Sistem

\begin{tabular}{|c|c|c|c|}
\hline $\begin{array}{c}\text { DATA RIIL HASIL } \\
\text { KEPUTUSAN } \\
\text { PENENTU }\end{array}$ & $\begin{array}{c}\text { HASIL } \\
\text { PERHITUNGAN } \\
\text { SISTEM }\end{array}$ \\
\hline $\begin{array}{c}\text { Nama } \\
\text { Alternatif }\end{array}$ & Keterangan & Total Nilai & Ranking \\
\hline Alternatif 1 & SAMA & 5.6894 & 3 \\
\hline Alternatif 2 & $\begin{array}{c}\text { TIDAK } \\
\text { SAMA }\end{array}$ & 4.5264 & 13 \\
\hline Alternatif 3 & $\begin{array}{c}\text { TIDAK } \\
\text { SAMA }\end{array}$ & $\begin{array}{c}4.79437562 \\
5\end{array}$ & 12 \\
\hline Alternatif 4 & TIDAK & 5.12094240 & 7 \\
\hline Alternatif 5 & SAMA & 3 & \\
\hline Alternatif 6 & SAMA & 5.2769 & 8 \\
\hline Alternatif 7 & SIDAK & 5.6339 & 4 \\
\hline Alternatif 8 & SAMA & 4.1480 & 15 \\
\hline Alternatif 9 & SAMA & 5.7171 & 2 \\
\hline Alternatif 10 & SAMA & 5.5844 & 5 \\
\hline Alternatif 11 & TIDAK & 5.3384 & 7 \\
\hline & SAMA & 5.0586 & 11 \\
\hline Alternatif 12 & SAMA & 5.4689 & 6 \\
\hline Alternatif 13 & SAMA & 5.7335 & 1 \\
\hline Alternatif 14 & SAMA & 5.2713 & 9 \\
\hline Alternatif 15 & TIDAK & 4.1773 & 14 \\
\hline
\end{tabular}

Dapat dilihat Tabel 5 bahwa dari total data alternatif yaitu 15 alternatif, terdapat 6,7\% alternatif yang lolos, 53,3\% alternatif yang baik, dan $40 \%$ alternatif yang tidak lolos.

\section{PENUTUP}

\subsection{Kesimpulan}

Berdasarkan dari uraian diatas, dapat ditarik kesimpulan dari beberapa kesimpulan sebagai berikut :

1. Terciptanya suatu Sistem Pendukung Keputusan Pengadopsian Anak Menggunakan Metode Analytical Hierarchy Process (AHP) Dan Metode Perbandingan Eksponensial (MPE). Dapat memberikan kemudahan dalam menghitung nilai perbandingan dari alternatif-alternatif atau calon orangtua tersebut dengan waktu yang lebih cepat.

2. Berdasarakan hasil pengujian menggunakan pengujian fungsional (BlackBox) yang telah dilakukan pada masing-masing fungsi. Dapat disimpulkan bahwa aplikasi sistem pengadopsian anak berjalan sesuai dengan fungsinya.

3. Berdasarakan hasil pengujian menggunakan pengujian validitas dengan membandingkan data real dengan hasil perhitungan sistem menggunakan Metode Analytical Hierarchy Process (AHP) Dan Metode Perbandingan Eksponensial (MPE). Menunjukkan bahwa aplikasi sistem pengadopsian menggunakan Metode Analytical Hierarchy Process (AHP) Dan Metode Perbandingan Eksponensial (MPE) memiliki kinerja yang baik. Sehingga valid diterapkan dilembaga YPAB.

4. Total data alternatif yaitu 15 alternatif, terdapat $6,7 \%$ alternatif yang lolos, 53,3\% alternatif yang baik, dan $40 \%$ alternatif yang tidak lolos.

\subsection{Saran}

Adapun beberapa saran agar aplikasi tersebut dapat berguna dengan baik sebagai berikut:

1. Hasil sistem pemilihan calon pengadopsi sebaiknya hanya dijadikan alat bantu untuk mempermudah proses pemilihan calon pengadopsi dan tidak memakan waktu yang lama, untuk keputusan calon pengadopsi yang sangat layak tetap ditangan pengambil keputusan.

2. Penelitian ini disarankan dapat menjadi sebuah panduan atau acuan penelitian selanjutnya yang menggunakan metode yang sama dengan peneliti.

3. Penelitian selanjutnya diharapkan menggunakan metode yang sama namun hanya beda subjek saja.

\section{DAFTAR PUSTAKA}

[1] R. Umar, A. Fadlil, and Y. Yuminah, "Sistem Pendukung Keputusan dengan Metode AHP untuk Penilaian Kompetensi Soft Skill Karyawan," Khazanah Inform. J. Ilmu Komput. dan Inform., vol. 4, no. 1, p. 27, 2018.

[2] L. Prihartanto, "Sistem pendukung keputusan penerima jamkesmas metode ahp," Komun. dan Inform., pp. 1-17, 2016.

[3] E. Rosiska and R. Harman, "Metode Analitical Hierarchy Process (AHP) Dalam Pemilihan Umum Presiden Indonesia 2019," InfoTekJar (Jurnal Nas. Inform. dan Teknol. Jaringan), vol. 3, no. 2, pp. 193-202, 2019.

[4] N. Wulandari and Chriswahyudi, "Metode Perbandingan Eksponensial (Mpe) Untuk Menentukan Supplier Dan Activity Based Costing (Abc) Untuk Menentukan 
Produk Yang Menguntungkan Serta Uji Hedonik Untuk Mengetahui Pengaruh Bahan Baku Dari Supplier Yang Berbeda Terhadap Organoleptik Produk Di Pt. Xyz,"

Jurnal.umj.ac.id/index.php/semnastek, vol. 17, no. Sistem Pengambilan Keputusan, pp. 1-13, 2018.

[5] E. Darmanto, N. Latifah, and N. Susanti, "Penerapan Metode Ahp (Analythic Hierarchy Process) Untuk Menentukan Kualitas Gula Tumbu," Simetris J. Tek. Mesin, Elektro dan IImu Komput., vol. 5, no. 1, p. 75, 2014.

[6] A. Armiyana and R. M. Candra, "Sistem Pendukung Keputusan Pemilihan Sekolah Anak Dengan Menggunakan Metode Analytical Hierarchy Process (AHP) Dan Metode Perbandingan Eksponensial (MPE)," J. CorelT J. Has. Penelit. IImu Komput. dan Teknol. Inf., vol. 3, no. 1, p. 31, 2018.

[7] S. S. Wicida, "Sistem penunjang keputusan menentukan pilihan asuransi investasi menggunakan metode perbandingan eksponensial," pp. 16-19, 2017.

[8] B. R. Indra and H. Fauzi, "Dalam Sistem Pendukung Keputusan Penerima Beasiswa," vol. 3, no. 1, pp. 17-22, 2018.

[9] S. A. Irnanda Pratiwi \& Hermanto MZ, "Pemilihan Supplier Terbaik Penyedia Barang Consumbale Menggunakan Metode Analytical Hierarchy Process ( Studi kasus di Departemen Pengadaan Barang PT . PUSRI )," pp. 147-158, 2018.

[10] E. Yulianti and F. Juwita, "Jurnal TEKNOIF ISSN : 2338-2724 Sistem Pendukung Keputusan Pemilihan Tempat Kuliner di Kota Padang Menggunakan Metode Perbandingan Eksponensial (MPE) ( MPE ) Jurnal TEKNOIF ISSN : 2338-2724," J. TEKNOIF, vol. 4, no. 2, pp. 51-58, 2016.

[11] N.- Narti, S. Sriyadi, N. Rahmayani, and M. Syarif, "Pengambilan Keputusan Memilih Sekolah Dengan Metode AHP," J. Inform., vol. 6, no. 1, pp. 143-150, 2019.

[12] H. H. Vanya Eka Syafitri, "Penerapan Metode Perbandingan Eksponensial (MPE) sebagai Alternatif untuk Menunjang Pemilihan Karyawan Terbaik pada PD. Tiaramas Glassindo," J. IDEALIS, vol. Vol.3 No.1, pp. 56-62,
2020.

[13] Komarudin, "Pengujian perangkat Lunak metode Black box berbasis partitions pada aplikasi sistem informasi di sekolah," J. Mikrotik, vol. o6, no. 3, pp. 02-16, 2016. 